\title{
MITIGASI DAN ADAPTASI STRUKTURAL BAHAYA BANJIR BERDASARKAN KEARIFAN LOKAL MASYARAKAT ACEH SINGKIL PROVINSI ACEH.
}

\author{
Nazli Ismail $\left({ }^{1,4 *}\right)$, Bakhtiar $\left({ }^{2}\right)$, Muhammad Yanis $\left({ }^{1,3}\right)$, Dian Darisma $\left({ }^{3}\right)$, Faisal Abdullah $\left({ }^{4}\right)$ \\ ${ }^{1}$ Research Center Ethnoscience, Universitas Syiah Kuala, Banda Aceh, Aceh, Indonesia \\ ${ }^{2}$ Graduate Program in Disaster Science, Universitas Syiah Kuala, Banda Aceh, Aceh, Indonesia \\ ${ }^{3}$ Department of Geophysical Engineering, Universitas Syiah Kuala, Banda Aceh, Aceh, Indonesia \\ ${ }^{4}$ Department of Physics, Universitas Syiah Kuala, Banda Aceh, Aceh, Indonesia
}

\section{ARTICLE INFORMATION}

$\begin{array}{ll}\text { Submitted } & : 22^{\text {nd }} \text { August, 2020 } \\ \text { Review } & : 27^{\text {th }} \text { October, 2020 } \\ \text { Accepted } & : 09^{\text {th }} \text { November, 2020 } \\ \text { Published } & : 15^{\text {th }} \text { December, 2020 } \\ \text { Available Online } & : \text { December, 2020 }\end{array}$

\section{KEYWORDS}

Local Wisdom; flood hazard; mitigation; adaptation; Aceh Singkil

\section{CORRESPONDENCE}

*E-mail: nazli.ismail@unsyiah.ac.id

\begin{abstract}
A B S T R A C T
Most of the Singkil communities live along the river banks. Their longterm experience has generated some local wisdom in flood hazard mitigation and adaptation. To revitalize the values of the local wisdom, we have researched Cingkam Village, Aceh Singkil District, Aceh Province. A descriptive exploratory method was used in this study. Field data were collected based on field observations, interviews with local communities, and in-depth interviews with community leaders and local government regarding knowledge, experience, implementation, and possibility of developing the local wisdom. The results showed that the Singkil community practice local wisdom on structural mitigation and adaptation in flood hazards. They constructed floating buildings, namely sapao metungkhang, lampung, and bagan, made of logs drifting along the river. The buildings are practically effective, so that daily household and communal activities can still be carried out both in normal conditions and during flooding. However, they tend to disappear due to several factors including shortages of raw materials, progress inland transportation development, relocation of community far from rivers, and dimmed water transportation routes. Although the practices are starting to be abandoned, they still have the potential to be preserved and developed for both flood risk reduction and tourism destinations.
\end{abstract}

\section{A. PENDAHULUAN}

elama ini, kegiatan pengurangan risiko bencana lebih banyak difokuskan pada pengkajian alam secara fisis, namun itu tidak memberikan hasil yang lebih signifikan (Mayhura, et al., 2013). Oleh karena itu, gagasan ketahanan yang menekankan pentingnya komu nitas untuk 'membangun kembali dengan lebih baik' $^{1}$ dan untuk pulih dari bencana dengan sedikit atau tanpa bantuan eksternal adalah salah satu solusi untuk upaya pengurangan risiko bencana. Dengan alasan demikian, sistem penge tahuan adat semakin dianggap penting dan menjadi salah satu unsur kunci, sebagaimana

\footnotetext{
${ }^{1}$ UNISDR. Building the resilience of nations and communities to disasters: Hyogo framework for action 2005-2015. In: World Conference on Disaster Risk Reduction, UNISDR, 2005.
}

tercermin dalam sub-teks Kerangka Aksi Hyogo tahun 2005 sebagai bagian dari seruannya untuk membangun ketahanan bangsa dan masyarakat terhadap bencana.

Ada banyak istilah yang dapat disamakan dengan pengetahuan adat. Sebagian peneliti menyebutkannya sebagai pengetahuan lokal (misalnya, Gaillard \&, Mercer, 2012; Mercer et al., 2012; Cadag \& Gaillard, 2012). Namun demikian, secara antropologi Sillitoe (1998) me nyebutkan istilah ini dalam sebutan yang lebih luas, seperti pengetahuan tradisional, pengeta huan teknis asli, pengetahuan petani, dan pengetahuan lingkungan tradisional atau pengetahuan rakyat. $\mathrm{Di}$ Indonesia, istilah pengetahuan lokal juga sering disebutkan dengan kearifan lokal, seperti yang dipakai dalam makalah ini.

Terlepas dari keragaman makna, istilah tersebut menunjukkan bahwa kearifan lokal yang ada di dalam atau diperoleh oleh masyarakat 
lokal selama periode waktu tertentu dan di turunkan dari generasi ke generasi (Mercer, et al., 2010). Kearifan lokal cenderung terikat secara lokal, budaya dan konteks tertentu, nonformal dan ditularkan secara lisan, terkait erat dengan kelangsungan hidup dan penghidupan, dinamis dan berdasarkan inovasi, adaptasi dan eksperimen. Hal ini menunjukkan bahwa kearifan lokal adalah sumber daya berharga yang melekat, dan mekanisme bertahan yang diba ngun selama berabad-abad. Oleh karena itu, para peneliti mulai menggali kembali nilai-nilai kearifan lokal untuk diperkenalkan dan kemung kinan dipraktikkan secara luas, sebagai contoh kajian kearifan lokal terkait pengelolaan hutan adat (Tresno, et al, 2018).

Bentuk lain dari isu-isu lingkungan yang telah berkembang luas dan menjadi topik tersendiri adalah kajian tentang bencana alam. Kearifan lokal yang berkaitan dengan bencana alam banyak diperbincangkan dalam beberapa tahun terakhir, baik di Indonesia (Zamroni, 2011; Utama, 2013; MacAdoo, et al., 2006) maupun di negara-negara lain (Hussain, et al., 2015; Leonard, et al., 2013; Dube \& Munsaka, 2018).

Pentingnya sistem pengetahuan adat juga telah menjadi perbincangan khusus dalam ben cana banjir, sebagai contoh kajian tentang kemungkinan peningkatan kejadian banjir akibat perubahan iklim antropogenik melalui curah hujan yang tinggi, peningkatan basah daerah tangkapan dan kenaikan permukaan laut (Wilby \& Keenan, 2013). Sedangkan Hiwasaki, et al. (2014) menilai bahwa kearifan lokal sebagai salah satu cara untuk mengurangi dampak bencana alam. Dalam bentuk aplikasi yang praktis, masyarakat Turpan di Provinsi Xinjiang, Cina menerapkan teknologi karez sebagai bentuk karifan lokal dalam pengurangan risiko bencana kekeringan (Fang, et al., 2008) dan masyarakat Nandeswar, Banglades yang menanam tanaman bambu di sepanjang sungai untuk mitigasi bencana banjir (Stephen, et al., 2008).

Berdasarkan hasil beberapa kajian tersebut, dapat ditarik kesimpulan bahwa keberhasilan dan keberlanjutan dalam upaya pengurangan risiko bencana sangat bergantung pada ketersediaan budaya lokal yang relevan, pengetahuan dan praktik adat yang dapat digabungkan dengan ideide baru untuk menghasilkan inovasi.

Perserikatan Bangsa-Bangsa telah mema sukkan kearifan lokal dalam Prioritas 3 Kerangka Aksi Hyogo, kemudian diperbaharui dalam Ke rangka Aksi Sendai ${ }^{2}$ yang berfokus pada pen didikan dan pengetahuan. Salah satu kegiatan utama yang diidentifikasi di bawah tindakan prioritas ini berfokus pada pentingnya penge lolaan dan pertukaran informasi, dan menyoroti

\footnotetext{
${ }^{2}$ UNISDR, 2015, Sendai Framework for Disaster Risk Reduction
} 2015-2030, UNISDR, Geneva

277 | P a g e

https://doi.org/10.25077/jantro.v22.n2.p276-285.2020 penggunaan "pengetahuan tradisional dan adat yang relevan dan warisan budaya" untuk dibagikan dan disesuaikan dengan khalayak sasaran yang berbeda. Dengan meningkatkan pemahaman tentang kearifan lokal dan mem berikan contoh konkret tentang bagaimana upaya pengurangan risiko bencana dapat ditingkatkan, sehingga dapat menginspirasi semua praktisi dan pembuat kebijakan untuk mempertimbangkan pengetahuan yang dimiliki oleh masyarakat lokal dan bertindak untuk mengintegrasikan kekayaan pengetahuan ini.

Pada artikel ini disajikan hasil-hasil investigasi kearifan lokal masyarakat Cingkam, Kecamatan Gunung Meriah, Kabupaten Aceh Singkil, Provinsi Aceh, yang berhubungan dengan mitigasi dan adaptasi bencana banjir. Dalam satu dekade terakhir, intensitas dan kuantitas ancaman banjir di Singkil semakin tinggi ${ }^{3}$. Masyarakat Cingkam yang berdomisili di daerah aliran Sungai Lae Cinendang secara turun-temurun dihadapkan pada realitas untuk beradaptasi dengan banjir tahunan. Pengalaman seperti ini telah melahirkan bentuk kearifan lokal dalam upaya mitigasi dan adaptasi bahaya banjir. Dalam tulisan ini dibahas beberapa temuan kearifan lokal terkait dengan adaptasi dan mitigasi struktural terhadap bencana banjir. Pembahasan meliputi bentuk-bentuk struktural dan fungsinya yang terkait dengan upaya mitigasi dan adaptasi bahaya banjir, kondisi dan keberlangsungan kearifan lokal tersebut pada saat ini, alasan kearifan tersebut mulai ditinggalkan, potensi pengembangan struktur tersebut untuk pengurangan risiko bencana ke depan dan pemanfaatannya untuk aspek pariwisata yang dapat menunjang perekonomian masyarakat.

\section{B. METODE PENELITIAN}

$\mathrm{P}$ enelitian ini didesain sebagai penelitian deskriptif eksploratif yang melakukan penyelesaian masalah berdasarkan peng galian secara luas tentang hal-hal yang mempengaruhi terjadinya sesuatu berdasarkan fakta-fakta yang terjadi di lapangan. Dengan demikian, dalam penelitian ini kami telah meng gali, menjelaskan dan menggambarkan menge nai kearifan lokal mitigasi dan adaptasi struktural yang berkaitan dengan bahaya banjir. Penelitian deskriptif kualitatif dengan pendekatan etnografi merupakan penelitian yang termasuk ke dalam penelitian naturalistis atau bersifat alamiah (Cohen, et al., 2007).

Desain penelitian secara detail dijelaskan sebagai berikut. Tahap awal dilakukan peng kajian kepustakaan tentang pengetahuan lokal

\footnotetext{
${ }^{3}$ BPBA. (2016). Kajian Risiko Bencana Aceh 2016-2020, Badan Penanggulangan Bencana Aceh (BPBA), Banda Aceh.
} 
terhadap bahaya banjir. Berdasarkan hasil kepustakaan tersebut dilakukan akuisisi data primer pada Bulan Maret 2020, di Desa Cingkam, Kecamatan Gunung Meriah, Aceh Singkil (Gambar 1). Data primer yang dikumpulkan berupa observasi lingkungan dan wawancara dengan masyarakat yang tinggal di sepanjang Sungai Lae Cinendang, serta wawancara mendalam dengan informan kunci. Tiga metode pengumpulan data memungkinkan untuk triangu lasi, yang memverifikasi, menguatkan, meningkat kan kredibilitas dan kepercayaan atau validitas data (Gershberg, 1998; Gibson, 2004).

Wawancara mendalam dilakukan dengan informan kunci yang terdiri dari satu orang tokoh adat, satu orang pemuka masyarakat dan Kepala Badan Penanggulangan Bencana Daerah (BPBD) Aceh Singkil. Pertanyaan yang diajukan terkait dengan kondisi sosial budaya masyarakat Singkil, keberadaan sungai Lae Cinendang dengan kehidupan sosial masyarakat, kearifan lokal masyarakat terkait banjir, program-program pemerintah terkait dengan penanggulangan bencana banjir, sikap masyarakat terhadap program,-program tersebut, arah pembangunan daerah terkait penanggulangan bencana, upayaupaya pemerintah dan komunitas adat terhadap pelestarian kearifan lokal serta pengembangan nya untuk pariwisata. Data yang diolah dalam penelitian ini hanya yang terkait dengan mitigasi dan adaptasi struktural saja.

Observasi lingkungan di sepanjang Sungai Lae Cinendang dilakukan berupa pengamatan kondisi fisik sepanjang bantaran sungai, penga matan dan pengambilan foto detail rumah sapao metungkhang berserta struktural lain yang ada di sekitarnya, bangunan lampung, dan bagan. Sedangkan wawancara dengan 20 orang perwakilan masyarakat yang tinggal di sepanjang Sungai Lae Cinendang dilakukan pada pemilik rumah sapao metungkhang, lampung, dan bagan. Pertanyaan yang diajukan terkait dengan sejak kapan bangunan tersebut dibangun?, Apa alasan bangunan tersebut dibangun?, Mengapa bangunan tersebut masih dipertahankan? Apa kah mereka mendapatkan manfaat dari bangu nan tersebut? Apakah bangunan tersebut akan dipertahankan pada masa mendatang? Apakah ada tawaran dari pemerintah untuk relokasi? Bagaimana pandangan mereka dengan program relokasi? Dan sejauh mana pandangan mereka dengan program pengembangan bangunan terse but untuk pariwisata?

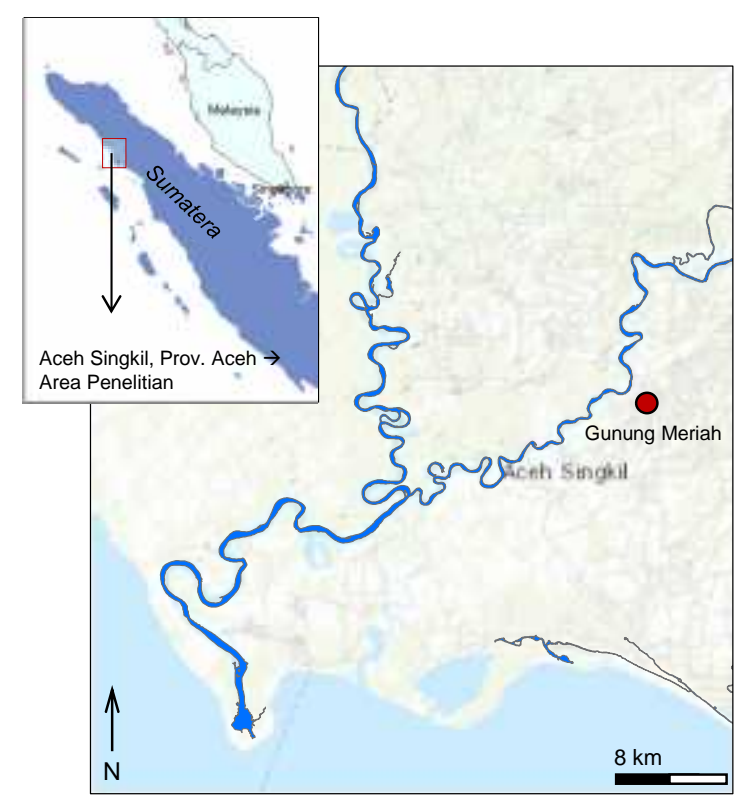

Gambar 1. Peta lokasi penelitian, Kecamatan Gunung Meriah, Aceh Singkil (merah), sungai Lae Cinendang ditujukkan oleh garis biru.

\section{HASIL DAN PEMBAHASAN}

\section{Keadaan Geografi dan Demografi}

A ceh Singkil merupakan salah satu kabupaten di Provinsi Aceh yang multi kultur. Penduduk Aceh Singkil terdiri dari suku Aneuk Jamee yang umumnya berdiam di pesisir pantai, suku Boang atau sering disebut Orang Kampung yang bermukim di pedalaman atau pinggiran sungai, dan suku Pakpak yang Sebagian besar tinggal pada pusat-pusat kecamatan. Selain itu terdapat juga etnis Aceh, Jawa, Batak dan Minangkabau. Keberagaman budaya ini telah membuat Singkil terkenal sejak masa lampau ke seluruh Nusantara (Ahmad, 2016).

Wilayah penelitian ini mengambil tempat di Kecamatan Gunung Meriah yang umumnya didominasi oleh suku Boang dan Pakpak. Pada wilayah ini, masyarakat umumnya bermukim di Rimo sebagai pusat kecamatan dan sepanjang Sungai Lae Cinendang. Lokasi Kecamatan Gunung Meriah termasuk wilayah pedalaman di Kabupaten Aceh Singkil (Gambar 1).

Pada umumnya, topografi wilayah Kabu paten Singkil terbagi dalam wilayah daratan dan kepulauan. Sedangkan wilayah daratan didomi nasi oleh kawasan pedalaman dan kawasan pesisir. Pada wilayah pedalaman pun, masyara kat lebih banyak bermukim di sepanjang sungai. Dengan demikian, baik wilayah kepulauan maupun wilayah pesisir dan pedalaman, kehidu pan masyarakat Singkil umumnya berada di sepanjang aliran air, baik daerah pesisir maupun sepanjang aliran sungai. 
Terdapat dua sungai besar yang terkenal, yaitu Sungai Lae Soraya dan Sungai Lae Cinendang. Kedua sungai ini sebenarnya satu. Aliran ke hulu pada arah kiri disebut Lae Souraya atau dikenal dengan Simpang Kiri. Sedangkan ke hulu arah kanan disebut Lae Cinendang atau dikenal dengan Simpang Kanan. Hulu Lae Cinendang berada di Kabupaten Pakpak Bharat dan Humbang Hasundutan, Propinsi Sumatera Utara dan keduanya menyatu menjadi Lae Cinendang. Lae Cinendang adalah sungai terbesar di Provinsi Aceh dan juga sungai terbesar di belahan barat Pulau Sumatera.

Dalam perjalanan sejarah, Lae Cinendang tidak dapat dipisahkan dengan kehidupan masyarakat. Mereka menyebut sungai ini dengan istilah tapin. Pada Abad XV, Lae Cinendang merupakan jalur transportasi penting kapal-kapal dagang. Banyak kapal tipe lancaran dam jung menyusuri sungai dari Barus untuk berdagang. Lancaran adalah perahu asli Nusantara yang mampu bergerak cepat, sedangkan jung adalah perahu besar yang diadopsi dari Cina. Jung terbuat dari kayu yang dilengkapi dengan layer dan bubung dipakai untuk transportasi penum pang dan barang pada masa lalu.

Pada masa modern, sebelum tahun 2000an, Lae Cinendang masih digunakan oleh nelayan untuk mencari ikan, masyarakat untuk membeli kebutuhan sehari-hari, dan jalur petani yang berladang. Selain itu, jalur transportasi Lae Cinendang juga digunakan untuk prosesi adat seperti mengakhak atau menjalang, yaitu mengantar rombongan mempelai pada acara perkawinan, serta kegiatan adat bagahen ketika menghadiri undangan kenduri.

Pada masa penjajahan Belanda, jalur transportasi sungai sebagai satu-satunya jalur transportasi pada saat itu juga memiliki peran yang sangat penting dalam perjuangan. Bentuk sungai Lae Cinendang yang berkelok-kelok dan bercabang telah dipahami dengan baik oleh pejuang lokal, sehingga sering dijadikan sebagai taktik dan muslihat dalam berperang. Kebera daan pohon-pohon besar di sepanjang sungai dan arus sungai yang deras (sebak lae atau bellen lae) juga termasuk bagian lain yang digunakan pejuang lokal dalam berperang mela wan Belanda. Oleh karena itu keberadaan Lae Cinendang dengan masyarakat Singkil tidak dapat dipisahkan sepanjang masa.

Aliran sungai Lae Cinendang merupakan urat nadi kehidupan masyarakat Singkil. Selain itu, Lae Cinendang juga memberikan kontribusi yang sangat besar dengan permasalahan banjir di Singkil sepanjang masa. Berdasarkan ketera ngan masyarakat, banjir di sepanjang Sungai Lae Cinendang dapat terjadi sampai 20 kali per tahun. Namun kejadian tersebut tidak besar dan terbiasa bagi masyarakat. Banjir terbesar yang diingat oleh warga adalah pada tahun 2000 dan
2002, ketinggian air sampai menutupi jendela rumah atau sekitar 3 meter karena umumnya rumah di sepanjang sungai Lae Cinendang adalah rumah panggung. Oleh karena itu, pengalaman hidup yang cukup lama dengan kejadian banjir telah mampu mengajarkan masyarakat Singkil hidup berdampingan dengan banjir. Salah satu bentuk kearifan lokal yang dilahirkan adalah upaya mitigasi dan adaptasi terhadap bahaya banjir.

Berdasarkan dari lama dan kuatnya interaksi sosial budaya masyarakat yang bermukim di sepanjang sungai dengan keberadaan sungai Lae Cinendang maka dapat dikatakan bahwa keberadaan sungai Lae Cinendang merupakan bagian dari budaya masyarakat setempat. Budaya dapat didefinisikan sebagai cara hidup yang mengekspresikan makna dan nilai tertentu dari orang. Para antropolog memandang dunia sebagai bentuk kepingan-kepingan budaya dari budaya tradisional dan nilai-nilai yang diwariskan (Nanda dan Warms, 2007). Menurut Taylor (1924) dalam Kutalunga (2010), budaya adalah hal-hal yang meliputi pengetahuan, kepercayaan, seni, moral, hukum, adat istiadat dan kemampuan dan kebiasaan lain yang diperoleh manusia sebagai anggota masyarakat. Budaya juga dapat dilihat sebagai alat yang terdiri dari simbol, cerita, ritual, dan pandangan dunia yang dapat digunakan orang dalam situasi yang berbeda. Unsur-unsur dalam budaya ini diturun kan dari satu generasi ke generasi lainnya dan memberikan pedoman bagi individu untuk bertahan hidup dalam masyarakat (Hall et al., 2003).

Pada masyarakat yang hidup berdampingan dengan ancaman bencana alam, maka budaya terhadap upaya pengurangan risiko bencana alam muncul dan dipraktikkan dalam kehidupan sehari-hari. Kemampuan masyarakat beradaptasi dan melakukan mitigasi terhadap bencana sesuai dengan pengalaman dan jenis bencana yang sering terjadi dalam lingkungan masyarakat tersebut. Gempa bumi, tsunami, tanah longsor, banjir, dan badai termasuk jenis bencana yang sesuai dengan kondisi geologi Indonesia.

Di antara jenis-jenis bencana alam tersebut, banjir merupakan salah satu bencana yang sering terjadi di Indonesia. Peristiwa banjir dipandang sebagai hal yang biasa dibandingkan dengan bencana lain seperti gempa bumi dan tsunami, akan tetapi frekuensi dan dampak kerugian jiwa dan harta benda yang ditimbulkan sangat fatal. Kebiasaan masyarakat hidup berdampingan dengan kondisi alam tertentu dalam waktu yang sangat lama dapat melahirkan kearifan lokal pada masyarakat tersebut (Sullivan, 2016), dalam hal ini kearifan dalam bentuk mitigasi dan adaptasi terhadap bahaya banjir. 
Berdasarkan undang-undang, mitigasi dapat didefinisikan sebagai serangkaian upaya untuk mengurangi risiko bencana melalui pembangu nan fisik maupun penyadaran dan peningkatan kemampuan menghadapi ancaman bencana. Sedangkan adaptasi bencana alam ialah penyesuaian sistem alam dan manusia terhadap bencana alam yang terjadi, guna mengurangi dampak negatifnya ${ }^{4}$.

Dengan demikian, terkait mitigasi dan adaptasi struktural tersebut, masyarakat Singkil memiliki kearifan lokal tersebut, seperti kebera daan lampung dan bagan terapung yang masih ditemukan di sepanjang aliran sungai Lae Cinendang. Meskipun bangunan semacam itu pernah digunakan secara efektif dalam kehidu pan masyarakat Aceh Singkil, namun pada saat ini dampak banjir di Singkil semakin lama semakin bertambah. Hasil pengamatan dan wawancara di lapangan ditemukan 3 bentuk kearifan lokal mitigasi dan adaptasi struktural yang dibahas dalam artikel ini, yaitu rumah sapao metungkhang, lampung, dan bagan. Ketiga struktur tersebut adalah telah digunakan secara turun-temurun dalam kehidupan masyarakat Singkil.

\section{Rumah Sapao Metungkhang}

Rumah sapao metungkhang merupakan rumah panggung yang banyak dijumpai di sepanjang aliran Sungai Lae Cinendang (Gambar 2). Material bangunan untuk tiang, lantai dan dinding terbuat dari kayu, sedangkan atap terbuat dari daun rumbia atau seng. Secara vertikal lantai rumah terdiri dari kolong rumah, lantai utama, dan plafon. Ketiga bagian tersebut dapat difungsikan secara maksimal, baik dalam kondisi normal maupun kondisi darurat.

Aktivitas keluarga selama masa normal berlangsung di lantai utama rumah. Ketinggian lantai rumah sekitar 1-meter dari permukaan tanah. Terdapat tangga pada bagian depan rumah yang menghubungkan halaman rumah dengan teras (serambi). Bagian serambi diguna kan sebagai tempat menyambut tamu dan tempat bersantai keluarga. Serambi masih merupakan bagian luar dari rumah. Terdapat pintu utama dari serambi ke bagian dalam rumah. Bagian dalam rumah terdiri dari ruang tamu, ruang tidur, ruang tengah dan dapur pada bagian paling belakang.

\footnotetext{
${ }^{4}$ Undang-Undang No 24 Tahun 2007 Tentang Penanggulangan Bencana.
}
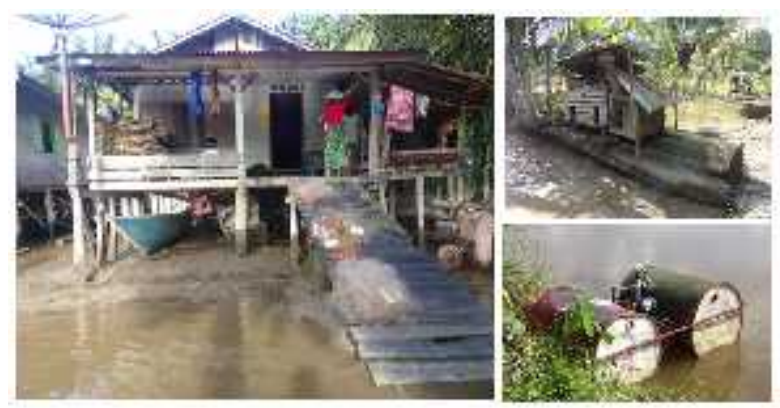

Gambar 2. Rumah Sapao Metungkhang (kiri), kandang ternak kayu bakar (kanan atas), dan mesin pompa air terapung (kanan bawah)

Dilihat dari struktur bangunan, rumah sapao metungkhang dimodifikasi sehingga dapat difung sikan untuk mitigasi dan adaptasi bahaya banjir yang sering terjadi di Singkil. Ketinggian rumah dibangun sesuai dengan sejarah ketinggian banjir yang pernah terjadi di daerah tersebut, sehingga rumah tersebut relatif aman jika sewaktu-waktu terjadi banjir. Pada saat kejadian banjir yang lebih tinggi dari biasanya, bagian plafon pada rumah sapao metungkhang juga dapat dimanfaatkan sebagai tempat evakuasi.

Ruangan yang ada di bagian plafon rumah disebut pakha dalam Bahasa Singkil. Ruangan pakha langsung berada di bawah atap. Pada dua sisi muka dan belakang pakha dilengkapi dengan jendela kecil, sehingga dapat mengurangi sua sana pengap dan panas di dalam ruangan. Meskipun jarang dihuni, ruangan pakha dileng kapi dengan tempat tidur dan dapur. Pada bagian dapur juga tersimpan cadangan kayu bakar yang menandakan masyarakat Singkil telah memiliki sikap kesiapsiagaan terhadap bahaya banjir. Pada bagian tengah lantai ruangan pakha terdapat pintu vertikal dan tangga darurat untuk akses ke dalam ruangan tersebut dari bagian utama rumah. Ruang pakha hanya digunakan pada kondisi darurat, saat terjadi banjir yang lebih besar dari biasanya.

Peristiwa banjir merupakan kejadian yang sangat sering di wilayah Singkil, oleh karena itu masyarakat setempat telah mampu melakukan proses adaptasi terhadap bahaya banjir dengan memanfaat kolong rumah sebagai salah satu tempat untuk kesiapsiagaan. Hampir semua rumah sapao metungkhang menambatkan pera hu di bawah kolong, meskipun tidak dalam keadaan banjir. Perahu tersebut difungsikan pada saat banjir terjadi sebagai sarana transportasi dari rumah ke tempat akses yang aman.

Kolong rumah juga difungsikan untuk menyimpan kayu bakar, kandang unggas, dan peralatan menangkap ikan di sungai seperti jala, jaring, dan bubu. Dengan demikian, Sebagian kebutuhan logistik rumah tangga sehari-hari dipasok dari bawah kolong rumah. Pengalaman banjir yang berkepanjangan memberikan inspirasi kepada masyarakat setempat untuk memitigasi dan beradaptasi dengan alam dalam 
wujud ketahanan pangan (food security). Bangunan kandang unggas, tempat penyim panan kayu bakar dan mesin pompa air dibuat di atas kayu gelondong atau ban mobil yang mampu mengapung jika sewaktu-waktu terjadi banjir (Gambar 2).

Ditinjau dari efektivitas rumah sapao metungkhang yang telah dijelaskan tersebut, maka rumah tradisional ini mempunyai prospek yang cukup baik untuk dikembangkan. Akan tetapi, ada beberapa kendala yang akan dihadapi jika dilakukan pengembangan. Kendala pertama adalah perubahan arah pembangunan yang dilakukan oleh pemerintah terhadap pemukiman. Sejak masa Orde Baru sampai sekarang, peme rintah setempat melakukan upaya pembangunan jalan darat, sehingga masyarakat berpindah pemukiman di sepanjang jalan tersebut. Bebe rapa kali upaya relokasi pemukiman juga telah dilakukan oleh pemerintah di tempat-tempat yang jauh dari sungai, sehingga pemukiman di sepanjang sungai mulai ditinggalkan. Kendala lain yang ditemukan adalah kekurangan bahan baku pembuatan rumah sapao metungkhang. Ketersediaan kayu pada saat ini semakin langka dan mahal, sedangkan pada zaman dulu masyarakat membangun rumah dengan meman faatkan gelondongan kayu yang hanyut dari sungai. Kebijakan larangan penebangan kayu oleh pemerintah juga telah berpengaruh secara signifikan terhadap ketersediaan kayu yang hanyut di sungai.

\section{Lampung}

Berbeda dengan sapao metungkhang yang di bangun di daratan sepanjang bantaran sungai, lampung merupakan bangunan terapung yang tertambat di aliran sungai. Bagian bawah lampung tersusun dari gelondongan kayu yang terikat satu sama lain dan mengapung di atas permukaan air sungai. Gelondongan tersebut ditambat pada pancangan kayu di sisi sungai sehingga tidak terbawa arus. Lantai bangunan disusun di atas gelondongan tersebut. Rumah apung dilengkapi dengan dinding dan atap sehingga layak ditempati.

Dalam pemanfaatannya, rumah apung ini, difungsikan sebagai dermaga tempat menam batkan perahu bagi pengguna jalur transportasi sungai. Sebelum tahun 2000-an, jalur sungai Lae Cinendang ini masih sering digunakan oleh masyarakat untuk sarana transportasi. Mereka menggunakan sampan atau boat bermesin untuk keperluan bepergian. Selain itu rumah apung juga difungsikan sebagai kedai terapung yang menyediakan berbagai kebutuhan masyarakat seperti makanan dan minuman. Oleh karena itu, lampung yang difungsikan sebagai warung kopi selalu penuh oleh pengunjung yang beristirahat setelah hilir mudik di sepanjang sungai. Lampung juga dapat difungsikan sebagai tempat salat dan sekaligus sebagai tempat tinggal bagi pemiliknya.

Konstruksi lampung merupakan bentuk lain kearifan lokal masyarakat Singkil terhadap bahaya banjir. Curah hujan yang tinggi di wilayah Singkil menyebabkan ketinggian dan arus sungai Lae Cinendang sangat cepat pada musim hujan. Dengan kondisi demikian, mengharuskan masya rakat Singkil melakukan upaya adaptasi dengan membangun lampung yang dapat menyesuaikan posisinya dengan ketinggian aliran sungai, sehingga dapat berfungsi dalam keadaan normal dan saat terjadi bahaya.

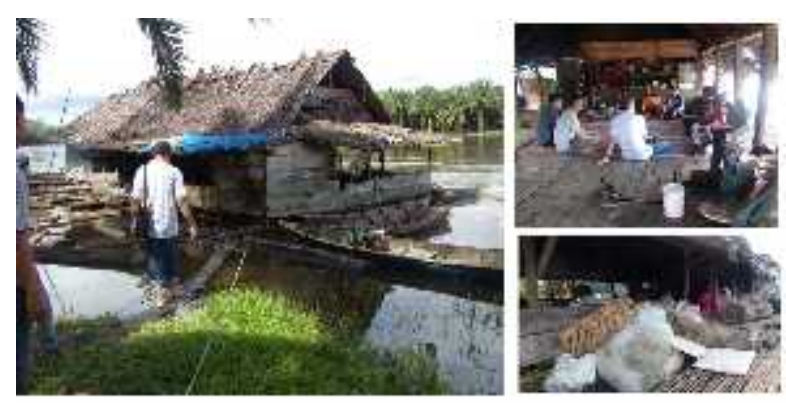

Gambar 3. Rumah Apung (kiri) bagian dalam berfungsi sebagai kedai dan tempat tinggal (kanan atas) dan sisi bangunan dimanfaatkan untuk menyimpan peralatan nelayan (kanan bawah).

Namun demikian, seiring dengan berku rangnya pemanfaatan jalur transportasi sungai, keberadaan lampung pada saat ini semakin sulit ditemukan di sepanjang aliran sungai Lae Cinendang. Dari 3 lampung yang masih tersisa di Kecamatan Gunung Meriah, lampung yang terdapat di Desa Tanah Merah merupakan yang tertua dan masih difungsikan sebagai warung kopi sampai saat ini.

\section{Bagan}

Jika bangunan sapao metungkhang dan lampung sekaligus difungsikan sebagai tempat tinggal, maka bagan apung merupakan bangu nan terapung yang hanya difungsikan untuk aktivitas masyarakat sehari-hari di pinggir sungai. Sungai bagi masyarakat Singkil adalah tempat untuk saling bertemu dan berinteraksi satu sama lain. Di pinggiran sungai masyarakat membuat bagan sebagai tempat yang bisa digunakan untuk membersihkan kebutuhan sehari-hari. Di atas bagan masyarakat mencuci baju, piring dan peralatan rumah tangga lainnya. Bagan juga difungsikan untuk tempat mandi buang air besar. Oleh karena itu bangunan ini dinamakan bagan dalam bahasa setempat yang berarti jamban 
dalam Bahasa Indonesia. Bagan secara khusus digunakan untuk tempat buang air besar disebut gelobo dalam bahasa setempat yang maknanya seperti toilet.

Bagan apung terdiri dari dua bagian, satu sisi berfungsi sebagai tempat mencuci pakaian atau menjemur padi, jagung dan produksi pertanian lainnya pada saat banjir. Bagan Apung juga difungsikan sebagai tempat memasak pada saat acara pesta perkawinan dalam kondisi banjir. Di dekat bagan biasanya dibangun rumah adat yang digunakan untuk acara pesta perkawinan. Oleh karena itu, menurut keterangan salah satu tokoh adat setempat, rumah adat Singkil dibangun pada saat pesta berlangsung. Rumah adat merupakan tatanan yang penting dalam prosesi pesta, "Kalau pesta tidak memakai adat maka tidak wajib di hadiri oleh sintua" katanya. Sintua adalah tokoh adat dalam tatanan sosial budaya Masyarakat Singkil. Kelebihan pesta adat dilakukan secara gotong royong di bawah koordinasi kepala desa. Ketika pesta adat berlangsung bertepatan dengan kondisi banjir, maka kegiatan pesta seperti menjamu tamu dan prosesi acara berlangsung sedangkan kegiatan memasak dilakukan di atas bagan. Karena terhalang oleh adanya banjir, mereka menggu nakan sampan untuk membagikan hidangan jamuan kepada tamu. Inilah salah kearifan lokal yang sangat unik yang ada dalam masyarakat Singkil, melakukan pesta di atas bagan.

Bagan apung juga dapat digunakan sebagai tempat untuk menambat perahu. Bahan-bahan yang digunakan untuk bagan apung juga berasal dari gelondongan kayu hanyut di sepanjang aliran sungai Lae Cinendang. Gelondongan tersebut kemudian diikat satu sama lain dengan tali dan dikaitkan dengan pasak pada tebing sungai, atau diikatkan pada kayu besar dengan tali tambang.

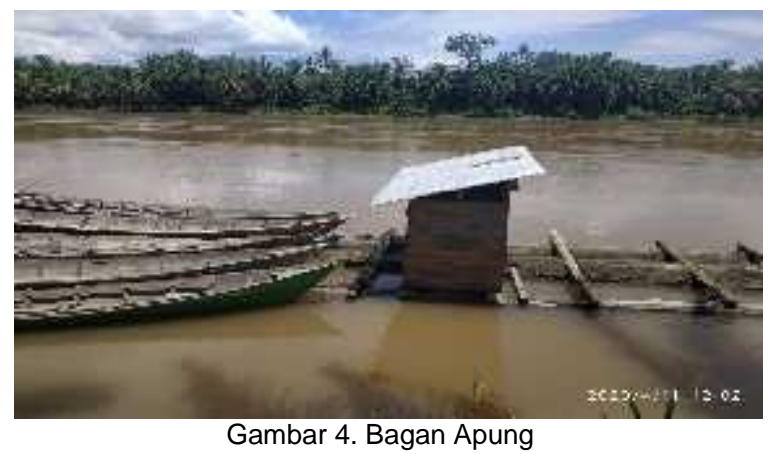

\section{Potensi pengembangan}

Kearifan lokal telah menjadi komponen inheren dari sistem manajemen bencana tradisional. Selama berabad-abad orang telah menyesuaikan kehidupan dan mata pencaharian mereka untuk beradaptasi dengan perubahan konteks dalam bentuk kearifan lokal. Meskipun kearifan lokal, dalam banyak hal, tidak selalu terlihat, masyarakat lokal memanfaatkannya untuk membangun dan merekonstruksi diri mereka sendiri guna mencegah, memitigasi, mempersiapkan, merespons, dan memulihkan dari dampak bencana. Ini dapat dianggap sebagai mekanisme bertahan dan merupakan cara di mana sekelompok orang atau individu menjadi tangguh dari bencana.

Membawa kearifan lokal lebih fokus dan konteks memperdalam pemahaman tentang bagaimana orang mengelola keadaan mereka sendiri yang berubah dan dapat membawa informasi yang lebih relevan tentang peristiwa bahaya itu sendiri, Mercer, et al. (2010) berpendapat bahwa kearifan lokal sangat berharga dalam memahami peristiwa bencana yang telah terjadi dalam kurun waktu yang lama dalam suatu masyarakat. Sementara itu, penge tahuan ilmiah telah terbukti sangat penting dalam menangani peristiwa langka atau belum pernah terjadi sebelumnya. Akibatnya, kearifan lokal dan pengetahuan ilmiah harus dianggap sebagai dua sisi mata uang yang sama, yang saling melengkapi.

Namun demikian, kearifan lokal dalam upaya mitigasi dan adaptasi terhadap bahaya banjir di Kabupaten Singkil mulai ditinggalkan sejak tahun 1980-an, karena jalur transportasi darat mulai menjangkau seluruh pelosok wilayah Singkil. Masyarakat mulai merelokasi tempat tinggal mereka ke wilayah daratan yang lebih tinggi. Relokasi penduduk ini, difasilitasi oleh Pemerintah Kabupaten Aceh Singkil dalam upaya membangun permukiman yang layak huni. Meskipun masih belum menemukan format yang tepat dalam upaya relokasi tersebut, namun pemerintah tetap melanjutkan relokasi warga dari bantaran sungai ke daratan, dengan berbagai macam tantangan yang harus dihadapi oleh masyarakat dan pemerintah.

Di samping itu, faktor ketersediaan bahan baku untuk pembuatan rumah dan prasarana lain yang bersumber dari gelondongan kayu yang hanyut saat banjir juga sudah semakin sulit diperoleh. Perubahan mata pencaharian dari sektor perikanan ke perkebunan kelapa sawit, juga menjadi salah satu penyebab masyarakat melakukan migrasi ke wilayah daratan yang lebih tinggi. Oleh karena itu sangat tipis kemungkinan pengembangan kembali bentuk-bentuk kearifan lokal tersebut jika ditinjau dari sisi efektivitas dan kubermanfaatnya bagi masyarakat setempat.

Bentuk kearifan lokal ini masih dapat dilestarikan untuk pelestarian nilai-nilai budaya dan pembangunan sektor pariwisata. Pembangu nan dan pelestarian kearifan lokal tersebut dapat mendongkrak pertumbuhan ekonomi dan penda patan asli daerah dari sektor pariwisata dengan menjadikannya sebagai destinasi wisata baru di Aceh Singkil. Pengembangan sektor wisata tersebut berpeluang besar untuk meningkatkan kesejahteraan masyarakat. Pada beberapa tem pat yang masyarakatnya memiliki tradisi hidup di 
sepanjang aliran sungai, seperti di Banjarmasin dan Bangkok, keberadaan bangunan terapung telah berhasil dikembangkan sebagai daya tarik wisata. Keberadaan pasar terapung di kedua destinasi wisata tersebut malah menjadi ikon tersendiri bagi para pengunjung.

Namun demikian, pengembangan daerah wisata tidak dapat dilakukan dengan mudah, mengingat kawasan sepanjang Sungai Lae Cinendang sebelumnya belum pernah dikem bangkan kegiatan-kegiatan serupa. Sukses tidak nya program tersebut tidak hanya datang dari pemerintah atau investor yang menggagas atau memberikan dana pengembangannya. Keberlang sungan suatu program sangat erat kaitannya dengan keterlibatan masyarakat lokal sebagai pelaku utama dalam kegiatan tersebut. Terkait dengan pengembangan ekonomi dari sektor wisata air ini, misalnya Zamzami (2016) dalam kajiannya tentang pengembangan wisata pesisir menyebutkan bahwa pengembangan masyarakat melalui penguatan pranata sosial adalah upaya pemberdayaan yang terencana, dilaksanakan dengan sadar dan serius. Dengan cara usaha bersama demikian akan dapat memperbaiki kera gaman sumber pendapatan masyarakat. Pola pemberdayaan mereka diselaraskan dengan arah kesepakatan bersama. Partisipasi aktif secara kelembagaan akan melahirkan rasa kepemilikan setiap anggota masyarakat yang terlibat. Sehingga pelaksanaan program dapat berjalan semestinya. Akan tetapi, hal yang lebih penting lagi, keberhasilan pelaksanaan suatu pranata sosial masyarakat tertentu bukan hanya diukur dari pendapatan secara ekonomi masyarakat semata. Keberhasilan program yang seutuhnya terjadi ketika peran dan fungsi sosiokultural terjaga dengan baik.

Pemerintah dapat mengambil peran yang lebih dominan, untuk melestarikan kearifan lokal dalam upaya mitigasi dan adaptasi banjir. Hal tersebut akan menjaga kelangsungan dan diseminasi pengetahuan kepada generasi selan jutnya (Sujawarni, et al., 2018). Di samping itu, juga dapat menambah keuntungan dari sektor komersial wisatawan domestik dan mancanegara yang berkunjung ke Aceh Singkil. Kebijakan arah pembangunan yang dicanangkan oleh peme rintah dapat disinergikan dengan kearifan lokal yang ada. Keberlanjutan kearifan lokal tersebut akan tetap lestari sehingga dapat menambah khazanah budaya Indonesia pada umumnya dan Aceh pada khususnya. Seperti dikemukakan oleh Habibi dan Kusdarini (2020) bahwa kearifan lokal adalah bagian dari kebiasaan dan tradisi budaya sekelompok masyarakat. Tradisi tersebut lahir dalam berbagai bentuk seperti bangunan arsitektur dan kawasan pemukiman seperti yang terdapat pada masyarakat Singkil di sepanjang sungai Lae Cinendang. Kearifan lokal masya rakat Singkil tersebut unik, karena keunikan tempat, waktu, dan suku. Setiap komunitas memiliki tantangan alam dan kebutuhan hidup yang berbeda, sehingga melahirkan sistem pengetahuan lokal yang berbeda baik yang berkaitan dengan lingkungan di sekitarnya maupun dalam tatanan kehidupan sosial.

\section{KESIMPULAN}

$\mathrm{K}$ esadaran kolektif pada masyarakat Singkil menjadi salah satu hal yang mendorong terjaganya kearifan lokal dalam adaptasi dan mitigasi bencana banjir. Kearifan lokal yang masih dijaga oleh masyarakat Aceh Singkil adalah rumah panggung dengan menambah pakha (loteng), rumah apung, lampung, dan bagan apung. Dengan menjaga kearifan lokal ini, masyarakat telah mempersiapkan diri dengan segala kemungkinan anomali cuaca yang memang sulit diprediksi. Kearifan lokal ini tidak hanya menjaga tradisi atau adat-istiadat yang secara turun-temurun dilakukan namun juga memberikan sejumlah tata kelola hidup yang baik dan selaras dengan alam. Seiring dengan pesat nya pembangunan daerah yang meninggalkan pentingnya nilai-nilai kehidupan sungai, maka keberadaan rumah apung, lampung, dan bagan apung sebagai kearifan lokal dalam mitigasi dan adaptasi struktural terhadap bahaya banjir pun semakin langka. pada sisi lain, ketersediaan bahan baku juga telah menyebabkan salah satu ancaman punahnya tradisi tersebut. Pengem bangan kembali bentuk kearifan lokal ini dalam upaya pembangunan yang berkelanjutan perlu dilakukan, pada satu sisi untuk menjaga nilai-nilai budaya dan pada sisi lain dapat dikembangkan untuk pariwisata yang dapat mendongkrak eko nomi masyarakat.

\section{E. UCAPAN TERIMAKASIH}

$\mathrm{P}$ enelitian ini didanai oleh anggaran PNBP Universitas Syiah Kuala 2020 skim Penelitian H-Indeks. Terima kasih untuk Adnani, Zulfadli, Kendek Limbong, Muhammad Ikhsan, Aslim Kombih Bancin, Drs. H. Mu'adz Vohry, Salam Barus, Mukhtarudin, Abdul Latif, Tgk. Ikhsan, dan Badan Penanggulangan Bencana Daerah Kabupaten Aceh Singkil yang telah membantu dan memfasilitasi pengambilan data di lapangan.

\section{DAFTAR PUSTAKA}

Ahmad, H.A. (2016). Resolusi Konflik Keagamaan di Aceh Singkil dalam 
Perspektif Budaya Dominan. Jurnal Multikultural \& Multireligius, 15(3), 45-59.

Cadag, J.R.D. \& Gaillard, J.C. (2012). Integrating knowledge and actions in disaster risk reduction: the contribution of participatory mapping. Area, 44, 100-109.

Cohen, L., Manion, L. \& Morisson, K. (2007). Research Methods in Education 5th Edition. London and New York: Routledge Falmer.

Dube, E. \& Munsaka, E. (2018). The contribution of indigenous knowledge to disaster risk reduction activities in Zimbabwe: A big call to practitioners, Jàmbá: Journal of Disaster Risk Studies, 10(1), a493.

Fang, W., He, F., Cai, J., \& Shi, P. (2008). Karez Technology for Drought Disaster Reduction in China, dalam Shaw, R., Uy, N., and baumwoll, J. Indigenous Knowlegde for Disaster Risk Reduction: Good Practices and Lessons Learned from Experiences in The Asia-Pasific Region. Bangkok: UN/ISDR.

Gaillard, J.C. \&, Mercer, J. (2012). From knowledge to action: bridging gaps in disaster risk reduction. Progress in Human Geography, 37, 93-114.

Gershberg, A.I. (1998). Decentralisation, recentralisation and performance accountability: building an operationally useful framework for analysis. Development Policy Review, 16, 405-31.

Gibson, N. (2004). Action research. In: LewisBeck MS, Bryman A, Liao TF, editors. The sage encyclopaedia of social science research methods, vol. 1. Thousand Oaks: Sage, p. 4-6.

Habibi, R. K. \& Kusdarini, E. (2020). Kearifan lokal masyarakat dalam melestarikan tradisi pernikahan pepadun di Lampung Utara, Jurnal Antropologi: Isu-isu Sosial Budaya, 22(01), 60-69.

Hall, J. R., Neitz, M. J. \& Battani, M. (2003). Sociology on culture. New York: Routledge.

Hiwasaki, L. Luna E., Syamsidik, \& Shaw, R. (2014). Process for integrating local and indigenous knowledge with science for hydro-meteorological disaster risk reduction and climate change adaptation in coastal and small island communities. Int. J. Disaster Risk Reduction, 10, 15-27.

Hussain, Z., Al-shafie, H., Mita, H. A., Hussain, S., Hasan, M.M., \& Islam, G.M.K. (2015). Local wisdom: indegenous practices for mitigating disaster loss, Bangladesh, Proshar.

Kulatunga, U. (2010). Impact of Culture towards Disaster Risk Reduction, International Journal of Strategic Property Management, 14, 304-313.
Leonard, S., Parsons, M., Olawsky, K. \& Kofod, F. (2013). The role of culture and traditional knowledge in climate change adaptation: Insights from East Kimberley, Australia, Global Environmental Change 23, 623-632.

Mavhura, E., Manyena, S.B., Collins, A.E., \& Manatsa, D. (2013). International Journal of Disaster Risk Reduction, 5, 38-48.

McAdoo, B.G., Dengler, L., Titov, V., Prasetya, G. \& Smong, G. (2006). How an oral history saved thousands on Indonesia's Simeulue Island, Earthquake Spectra, 22 (Suppl 3), 661-669.

Mercer, J., Gaillard, J.C., Crowley, K., Shannon, R., Alexander, B., Day. S., et al. (2012). Culture and disaster risk reduction: lessons and opportunities. Environmental Hazards, 11, 74-95.

Mercer, J., Kelman, I., Taranis, L. \& SuchetPearson, S. (2010) Framework for integrating indigenous and scientific knowledge for disaster risk reduction. Disasters, 34, 214-39.

Nanda, S. and Warms, R. L. (2007). Cultural anthropology. Wadsworth/Thomson Learning, Belmont, CA.

Sillitoe, P. (1998). The development of indigenous knowledge: a new applied anthropology. Current Anthropology, 39, 223-252.

Sujarwani, R., Wulandari, F.D., Husni, A., Rianto, F., Sarinah. (2018). Pemberdayaan Masyarakat Komunitas Adat Terpencil (KAT) oleh Pemerintah Kabupaten Lingga, Kepualauan Riau, Jurnal Antropologi: IsuIsu Sosial Budaya. 20 (1): 17-31.

Sullivan (2016) Cultural Heritage and New Media: A Future for the Past, J. Marshal Rev. Intell. Prop. L. 604.

Stephen, I., Chowdhurry, R. D., and Nath, D. (2008). Soil and Water Conservation Throught Bamboo Plantation: A Disaster Management Technique Adopted by the People of Nandeswar, Assam, dalam Shaw, R., Uy, N., and baumwoll, J. Indigenous Knowlegde for Disaster Risk Reduction: Good Practices and Lessons Learned from Experiences in The AsiaPasific Region. Bangkok UN/ISDR.

Tresno, Ana, R.F., Wicaksono, M., Wicaksanti, A.R. and Deswita, R. (2018). Antara ulayat adat dan hutan nagari: Sebuah kebijakan perhutanan sosial di Minangkabau, Jurnal Antropologi: Isu-Isu Sosial Budaya, 20 (2), $191-211$.

Utama, B. (2013) Kearifan Lokal pada Arsitektur Hunian Tradisional di Kawasan Rawan Bencana Daerah Istimewa Yogyakarta. Kebudayaan, 8 (1), 40-56. 
Wilby, R.L. \& Keenan R. (2013). Adapting to flood risk under climate change. Progress in Physical Geography, 36, 348-78.

Zamroni, I. (2011). Islam dan Kearifan Lokal dalam Penanggulangan Bencana di Jawa. Penanggulangan Bencana, 2 (1), 1-10.,

Zamzami, L. (2016). Dinamika Pranata Sosial Terhadap Kearifan Lokal Masyarakat Nelayan Dalam Melestarikan Wisata Bahari, Jurnal Antrapologi: Isu-Isu Sosial Budaya, 18 (1): 57-67. 